\title{
Designing and Testing the Usability of NETA Prototype based on Fitts' Law: A preliminary Study
}

\author{
Gopi Doraisamy ${ }^{1}$, Dr. Balakrishnan Muniandy ${ }^{2}$ \\ ${ }^{1}$ Centre for Instructional Technology \& Multimedia, Universiti Sains Malaysia, Penang, Malaysia \\ gopima@gmail.com ${ }^{1}$ \\ ${ }^{2}$ Associate Professor, Centre for Instructional Technology \& Multimedia, Universiti Sains Malaysia, \\ Penang, Malaysia \\ mbala@usm.my ${ }^{2}$
}

\begin{abstract}
This paper is based on a study that was to design and test the usability of a tablet app prototype named NETA (Nota Elektronik Tatabahasa) as an assisting tool in Malay grammar learning process. For this purpose, an app prototype and a questionnaire consist of 26 items was developed based on the literature and expert opinions. Human-computer interface theories, usability theories and ID models such as Fitts' Law, ARCS Motivation Model, Gagne's Nine Events of Instruction and the Dick and Carey Instructional Design Model provided a basis for the development of the prototype and the questionnaire items. 40 form one students from a secondary school in the state of Penang, Malaysia filled the questionnaire. The Cronbach's alpha coefficient of the questionnaire was found to be .832 indicating a relatively high internal consistency and reliability of the items. The findings generally show that the NETA prototype helps to engage and motivate student to learn Malay grammar. The results also suggest that there are a number of areas for the NETA prototype to improve and promote the app in a more realistic manner that suits the needs of the students. Several recommendations are also presented for future research.
\end{abstract}

Keywords: Usability; Human-Computer Interface; Fitts' Law; ARCS Motivation Model

\section{Council for Innovative Research}

Peer Review Research Publishing System

Journal: International Journal of Management \& Information Technology

Vol. 9, No. 3

editor@cirworld.com

www.cirworld.com, member.cirworld.com 


\section{INTRODUCTION}

Researchers and designers of instructional materials always produce software to support learning in schools. Multimedia in language learning can promote Malay language learning (Kasiran, Siti Baidura \& Rosly, Nurul Jamilah, 2011) especially grammar. However, the intention of using the technology is not to replace the traditional ways of teaching and learning, but rather to provide an additional learning tool for some areas that require more attention, and those which have been identified as needing alternative methods, apart from the normal way of teaching (Syazwan Noordin, Wan Fatimah Ahmad, Yew Kwang Hooi, 2001).

Malaysian citizens aged 15 years and above have shown the highest intention to own a tablet among the countries of Southeast Asia (Nielsen Report, October 2011). In addition, Malaysia showed high use of free applications in the region. However, tablet applications for education in Malay grammar are not listed in the 200 most downloaded applications from the Apple Store and Android Market (App Annie, 2013). A robust tablet ownership without balance development of educational software detriment local education. These advantages should be used to develop tablet applications to aid the learning process of Malay grammar. There are many challenges in developing tablet applications. Many factors influence the success and failure of tablet applications.

The need for this research is critical because of the lack of tablet applications to help Malay grammar learning process. Student's readiness to accept the use of tablets in learning helps to ensure the success of these applications (Nielsen Report, October 2011). There are many usability studies on courseware for the desktop computers and laptops but guidelines established to study the usability of desktop computer software and laptop software cannot be used directly on the tablet applications. The intention of this research was focused on completing a tablet app named NETA which would be a prototype as a part of the Malay language grammar learning system.

\section{Background of Study}

Usability testing is a very important requirement in this research. NETA prototype is the first tablet based application to promote the learning of Malay grammar in the market of tablet applications. Usability of components to be tested is divided into five parts, namely learnability, efficiency, memorability, errors and satisfaction (Nielson 2003). The objective to create a tablet application with high usability was achieved by applying Fitt's Law in NETA interface design. If, as generally claimed, some consequences for user interface design include buttons and other GUI controls should be a reasonable size, top-of-screen menus are sometimes easier to acquire than top-of-window menus and pop-up menus can usually be opened faster than pull-down menus, since the user avoids travel. Prototype NETA development based on Fitt's Law was tested its usability by giving assignments to a sample of 40 students in form one. After completion of the test period, samples were given a questionnaire to be answered on NETA prototype usability.

\section{Statement of Problem}

Multimedia in language learning can promote Malay language learning (Kasiran, Siti Baidura \& Rosly, Nurul Jamilah, 2011). Lack of success to develop educational applications with high usability in helping student to learn grammar in schools has created dependency on existing resources that can be easily outdated and low in mobility (Pew Research Center's Internet \& American Life Reading Habits Survey, November 16-December 21, 2011). Although Malaysia is one of Southeast Asia's highest tablets user but it did not show its impact on education in general. Studies conducted on tablet ownership did not specify the percentage of tablet ownership in different age groups.

Teachers at a secondary school in Penang often face difficulties in teaching classification of nouns in Malay language to form one student. Existing reference source is a grammar dictionary but students feel bored and do not interest them. This situation delays the process of learning to move to next level. Use of multimedia should overcome this problem and yielded more positive results.

\section{Research Objectives}

The study was undertaken with the following objectives.

i. To design and construct a NETA prototype that will assist the learning of Malay grammar.

ii. To measure the student's motivation when using the NETA prototype in the learning of Malay grammar.

iii. To study the ease of use of the NETA prototype in assisting the learning of Malay grammar.

\section{Research Questions}

i. How is the student's motivation to use NETA prototype in assisting the learning of Malay grammar?

ii. How is the ease of use of the NETA prototype in assisting the learning of Malay grammar?

\section{Theoretical Framework}

The theoretical framework for the research is based on a combination of Keller's ARCS Model of Motivation and Fitts' Law. Motivational Design Theory asserts that instructional material should be configured with the strategies which increase the attention, relevance, confidence and satisfaction of the students for a instructional design which ensures the continuity of learning motivation (Keller, 1983). According to motivational design theory, in order to create an 
effective, efficient and attractive instructional design, the elements of motivation which are handled in four categories have to be understood well. Fitts' Law is an essential principle of Human-Computer Interaction theory that was formulated almost 60 years ago. It's critical to UX design for the desktop and laptop, but with interaction techniques being vastly different on mobile devices.

\section{Significance of the Study}

This research can help studied Malay grammar learning process. In addition, this research has the final product that can be used by teacher and student after testing. Although the study sample was composed of students, but also NETA full version can be used as a reference for teachers. Research conducted are necessary because the lack of Malay grammar applications in tablet application market. Usages of tablet applications are more significant than the use of traditional reference materials in learning Malay grammar. Time period of research plays a very important role in determining the scope of coverage of the grammar content and amount of samples to be tested. Content in the prototype reference material covers only a small part of the broad field of Malay grammar. This selection is considered relevant to the scope of research time and resources that exist.

\section{Limitations of the Research}

Research in the construction and testing of a prototype requires deep observation and sensitive to the needs of users. NETA's detail study was to get more accurate analysis of research to cover various levels of users. However, the existence of limitations is always an opportunity for follow-up research. Limitations of this study are as listed:

i. This research is limited to the study of Malay grammar for Form 1.

ii. This research is limited to the Malay language syllabus provided by the Ministry of Education, Malaysia.

iii. Software development is divided into design and evaluation to test usability. Results of the evaluation is limited to the institute where the study is carried out.

There are two main factors that influenced the limitations of the research. Firstly, the time period of research for about six months is appropriate for medium-scale research. Other form students cannot be tested due to the time constraints. Secondly, results of this study could answer the research question for this institute only. It exists because of the lack of financial resources in the provision of infrastructure to conduct research to the next level. All these limitations create space for further research to be done.

\section{LITERATURE REVIEW}

The literature review for this study covers the theoretical perspective, previous research in this area and the variables of the study.

\section{The ARCS Model of Motivational Design}

Motivation is a word derived from the Latin word movere, which means a case that led to the movement or change (Pintrich, 1996). According to Popovich (2000), motivation is a matter of cause one to move forward, and help solve a task. On the other hand, someone who does not have the motivation or desire motive on something, including learning. However, one teacher can change the learning environment so that students can motivate themselves. For example, in the teaching and learning process, are likely to occur in which a teacher teaches well, but students do not actually learn anything from it. Students will choose not to apply what they have learned; she has no interest in what was being learned.

According to Popovich (2000), motivation is an important quality that reflects success in learning and performance. Students who are motivated to learn will participate in all activities that help their learning. Over-motivation students often say that they already know or already know about a learning content. Importance of motivation as a positive influence on learning has been widely described in the literature (Keller, 1979: 1983). According Wlodkowski (1981) and Baker (2004), many recent studies relating to motivation focuses on identifying effective techniques for improving design, improving classroom management and meet the needs of different students. Researcher's motivation (learning-Motivation) applies some effective theories and concepts in the field of industry, to develop models of motivation to improve the teaching-learning environment (Small, 2000; Hyland, 2006).

According to Keller (1984) and Visser (1990), studies evaluating this model in application have provided evidence to support the validity of the four basic constructs and are solely for positive effects on student attitude and performance. ARCS model has also been applied in some kind of arrangement teaching (instructional settings) such as computerbased instruction (Keller \& Suzuki, 1988), textual material (Keller et al, 1987), instructor-led informal lecture (Visser et al, 1990) and online assessment (Hyland, 2006). Fernandez (1999) states, the ARCS model focuses on the conditions necessary to be sustained to keep the learner interested in the topic. According to Mills (2004) and Hyland (2006), the ARCS motivation model explains how students will work harder and learn more when they are motivated to do so.

\section{Fitts' Law and Mobile Interface Design}

Back in 1954, psychologist Paul Fitts published an article the detailed his theory on human mechanics as it pertained to aimed movement. It was Fitts' observation that the action of pointing to or tapping a target object could be measured and predicted mathematically. Fitts stated that the size of the target object along with its distance from the 
starting location could be directly measured, allowing him to model the ease at which a person could perform the same action with a different target object. In 1954, this theory had no application for computers yet; it can be used in conjunction with design theories such as visual weight to give user interface items proper hierarchy and placement. Fitts' Law is centered on a mathematical equation that is used to illustrate the time it takes to reach a target object. A target object, in the context of Uls, can be any interactive element, such as a submit button, a hyperlink, and an input field in a web form.

Bigger Is Not Always Better - One of the most important lessons we can take from Fitts' Law is that, while a larger button is clearly easier to click on, it isn't necessarily the most optimal. In web design, this means that a very small object will become significantly easier to click when given a $20 \%$ size increase, while a very large object will not share the same boost in usability when given the same $20 \%$ boost in size. Functionally and holistically, we know this isn't true.

Movement and Distances - Apart from size of the target object, another primary factor in Fitts' Law is the distance between where the mouse pointer currently is and where it needs to be. Additionally, the shorter distances between buttons that are similar to each other make them easier to use.

Prime Pixel - The key to optimizing user tasks is to know where the user is coming from before directing them elsewhere. This super pixel is aptly named the prime pixel, and as such, it yields the most power. For every user interface, the distance of a target object will always be measured by how far it is located from the prime pixel. For example, in Windows, any time user right-click inside desktop software, a contextual menu of options usually appears that has its point of origin at the prime pixel.

Grouping Items - It's important to keep interface items that are similar in close proximity to each other to reduce the distance between them, and thereby improving usability under the Fitts' Law model.

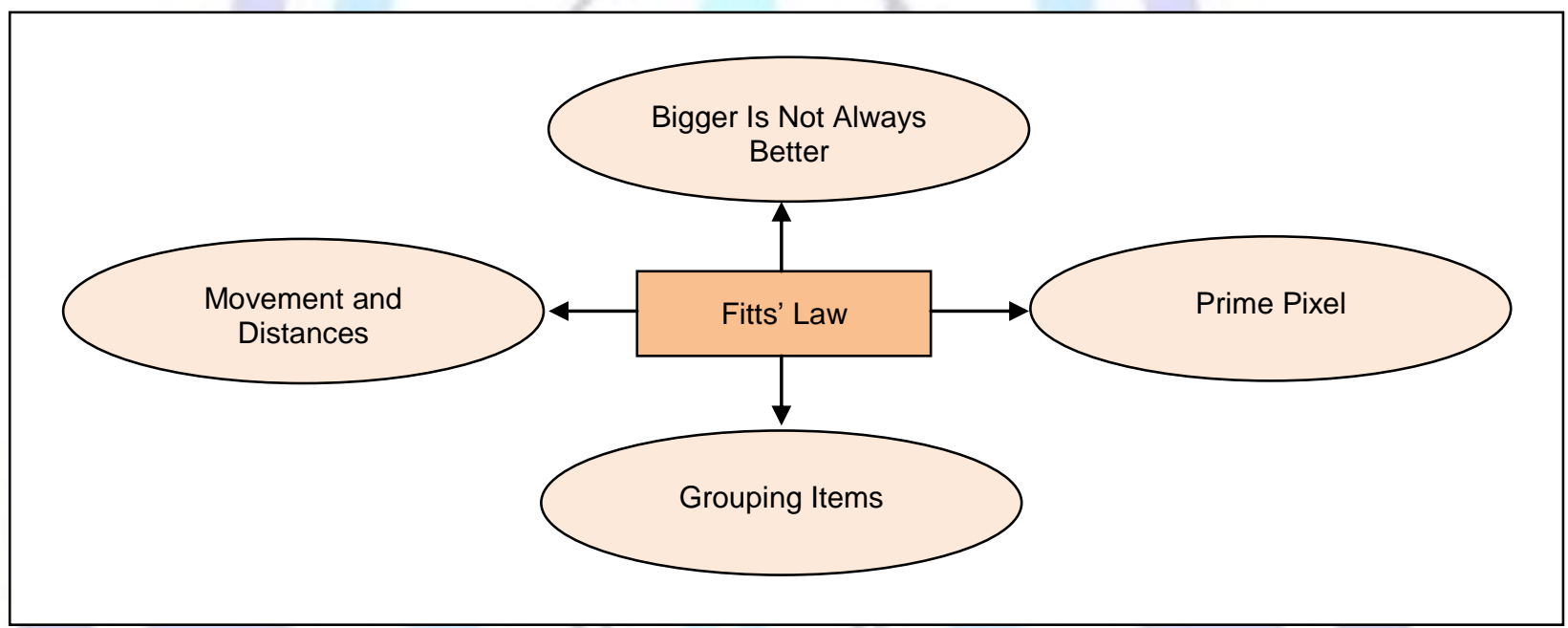

Figure 1. Components of Fitts' Law

Source: Adapted from Schmidt, R.A. (1991). Motor learning \& performance: From principles to practice

\section{Constructivist Theory}

According to members of constructivist theory, every man making principles, in their understanding of the mind, known as mental models according to existing experience (Jamalluddin Aaron \& Zaidatun Tasir, 2003). Some principles of learning emphasized by constructivist theory is that; Learning is a process of searching for meaning; Searching for the meaning of a thing requires a thorough understanding and also understanding of certain parts. Understanding of certain parts of the meaning here must be in the context of a comprehensive. Therefore, learning should focus on key concepts rather than as isolated facts; the purpose of learning is that individuals can build on their understanding of things. (Jamalluddin Aaron \& Zaidatun Tasir, 2003: 84). Students construct meaning of teaching activities (Simonson, 1997) and effective teaching based on authentic tasks that enable students construct learning environment that are meaningful to them. Application of constructivism in education is capable of producing students who can build understanding and new knowledge based on existing knowledge and experience, making students to understand more, confident and having fun to learn throughout life (Abdul Jalil Othman \& Bahtiar Omar, 2005).

\section{Application of Constructivist Theory in NETA Prototype Development}

This study aims to build a tablet based app to assist Malay grammar learning process among form one student in a secondary school based on Constructivist Theory. Technology support various aspects of social constructivist through collaboration in problem solving, allowing students to construct knowledge, learning in a meaningful context and linking learning with pupils experience (Rice \& Wilson, 1999). According to Rice and Wilson (1999:6) multimedia or hypermedia provides opportunities for cooperative learning, knowledge construction and learning occur in a meaningful context. The project provides an opportunity for students to be cooperative and collaborative learning 
happen in the classroom. Constructivist learning refers to the ability of students construct their own knowledge or actively concept based on existing knowledge (David \& Faridah Md Yusoff Hamat, 2002).

\section{Previous Research}

A considerable amount of literature has been published on usability of multimedia software in language studies. These studies produce a variety of multimedia development standards and approaches to appreciate the contribution of the field of multimedia. Although extensive research has been carried out on multimedia software, not much study exists which adequately covers usability of a tablet based apps in teaching and learning process. Researcher related the previous studies that address the research question of this paper.

The term human-computer interaction was popularized by Card, Moran, and Newell in their seminal 1983 book, "The Psychology of Human-Computer Interaction", although the authors first used the term in 1980,and the first known use was in 1975.The term connotes that, unlike other tools with only limited uses (such as a hammer, useful for driving nails, but not much else), a computer has many affordances for use and this takes place in an open-ended dialog between the user and the computer.

Surveys such as that conducted by Steven C. Seow (2005) showed that The Hick-Hyman Law and Fitts' Law are two surviving human performance principles based on Shannon and Weaver's (1949) Information Theory. In the early 1980s, Card, Moran, and Newell (1983) presented the laws as design principles for developers to maximize usability in the design of human-computer interfaces. A search of the current human-computer interaction $(\mathrm{HCl})$ literature, however, will reveal that the Hick-Hyman Law failed to gain momentum in the field of $\mathrm{HCl}$, whereas Fitts' Law received, and continues to receive, substantial attention. This article begins with a discussion the common information theoretical concepts of the two laws, and then examines each law with respect to its origins, theoretical formulation, theoretical development, research, and applications and examines the possible contributing factors responsible for the failure of Hick-Hyman Law to gain momentum in the field.

Jianfeng Wang \& Sylvain Senecal (2007) shows how, in the past, research into measuring perceived website usability was mainly concerned with the objective to develop a short, reliable, and valid perceived usability measurement scale. The aim is to develop a parsimonious scale that can be used across websites. Thus, the measurement scale could be used for benchmarking purposes within an organization and/or across organizations. Results suggested that the proposed website usability measurement scale has satisfactory psychometric characteristics. The scale also showed evidence of predictive validity by being positively correlated with participants' attitude toward the website.

Surveys conducted by Syazwan Noordin, Wan Fatimah Wan Ahmad \& Yew Kwang Hooi (2011) showed that tools based on Information Communication Technology (ICT) face serious usability problem for effective implementation in education delivery. The study was on a multimedia courseware using 3-Dimensional (3D) model for teaching a mathematical topic on Lines and Planes in 3-Dimensions. A field study with experimental approach was carried out on randomly selected students whereby a group of students was exposed to conventional learning, whereas the other group was aided with 3D visualization software. The study concludes that the latter group showed significant improvement in attention, response and recall of the content.

Qais Faryadi (2012) shows how, an experimental research that was aimed at developing an interactive multimedia courseware to be utilized in Malaysian classrooms. A courseware for interactive instructional design for learning Arabic was designed. The process of developing the software was divided into three phases, namely the conceptual phase, the conventional phase and the engineering phase. This paper discusses the second phase namely; the engineering phase. Furthermore, as this research utilized real life applications of the above models and theories of instructional design, the courseware design thus created and tested in the classroom. This multimedia interactive courseware could act as a prototype for future instructional design developers. This experimental phase discusses the empirical aspects of the finished product in an actual institution setting. Part three of this research was discussed the conventional methods of learning the Arabic language in an actual classroom setting.

\section{Variables of the Study}

\section{Ease of Use of the NETA Prototype}

Ease of use is one of the factors used to measure the usability of a system. Among the factors that are often used as a measure of usability is as follows: learnability, efficiency, memorability, errors, satisfaction, presentation, screen layouts, terms used and system capabilities. Development of a computerized system, usually involves two processes which are research and testing. The testing can increase the usability of the system by reducing the usability problems of the system design. Research and usability testing when done properly benefits, especially from the perspective of system development cost savings. Usability dimensions reviewed in the literature for interactive multimedia software include: ease of learning (Guillemette, 1995; Shackel, 1991). However, the nature and importance of these factors differ among groups of users and tasks performed. Learnability refers to "the ease with which new or occasional users may accomplish certain tasks" (Lindgaard, 1994). Users are quickly able to understand the most basic comments and navigation options and to use them to locate wanted information. In addition to easily understanding functionality of multimedia software, multimedia systems should be easy to remember. Effectiveness, measured in terms of speed and error, refers to levels of user performance (Lindgaard, 1994). After learning the multimedia software, users should become more expert at using them over time (Robertson, 1994).

\section{II.Motivation to Use NETA Prototype}


Multimedia software should be enjoyable to use and aesthetically pleasing to users. User satisfaction should be within acceptable levels of user cost in terms of tiredness, discomfort, frustration, and individual effort so that satisfaction causes continued and enhanced usage of multimedia software (Lindgaard, 1994). Motivational elements including typographical cueing, color, graphical images, animation, and sound in the interactive multimedia software can motivate the user and increase satisfaction, but follow the principles of motivational design elements (Lee \& Boling, 1996). A model specific to the field of education has been developed by Keller (1987), the ARCS model (Attention, Relevance, Confidence and Satisfaction), which focuses on creating, simulating and maintaining motivation for the use of teaching strategies. This model emphasizes the motivation and design strategies that can be applied by the designer or instructor direction, into the design of their teaching materials. According to Popovich (2000) and Hyland (2006), motivational strategies can be used to influence students' motivation to learn, and also, in solving problems related to learning. This can be done by allowing teachers to create a learning environment that motivated.

\section{RESEARCH METHODOLOGY}

\section{Research Design}

In designing the NETA prototype content, the measures to consider are the needs analysis of the form one students. In this study, researcher have analyzed some of the ideas in this study including the development of learning materials and assessment NETA prototype. Needs analysis is the premier step in finding the solution, in which the actual situation exists were compared with the situation and find the root causes of the problem and find ways to solve the problem (Raja Maznah Raja Hussain, 1990). Model to design Malay grammar learning materials used in the construction of NETA prototype is adapted from Dick and Carey model (Dick \& Carey, 1985).

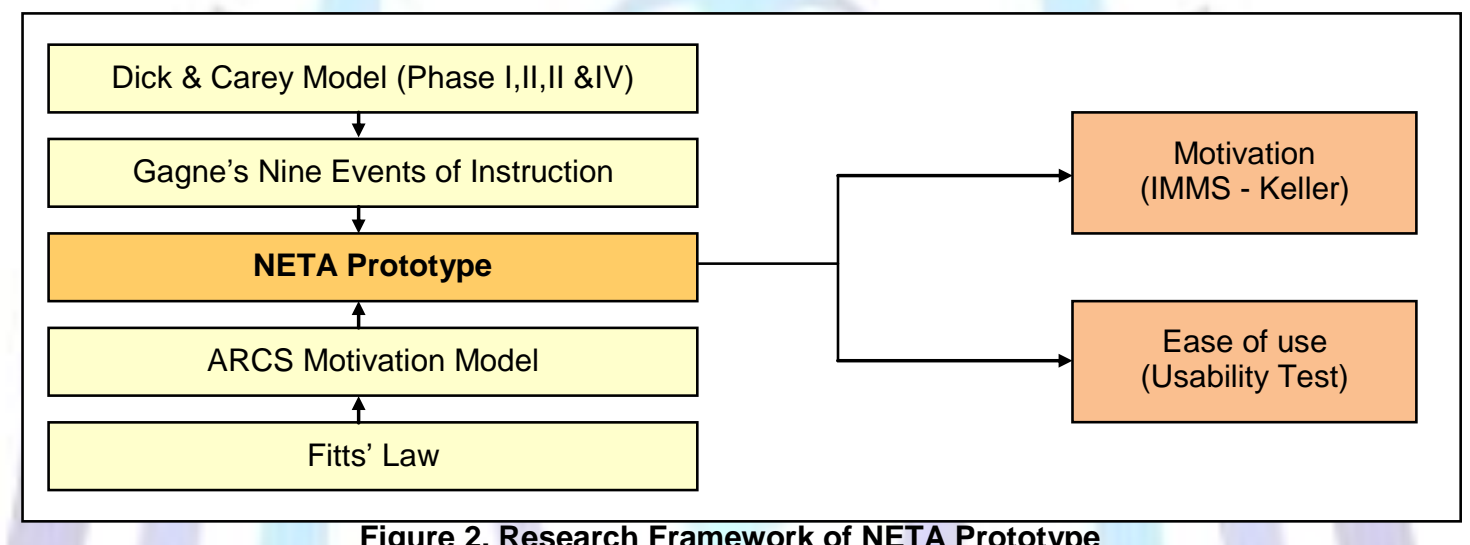

Figure 2. Research Framework of NETA Prototype

The model used in designing NETA prototype involves four distinct phases namely Phase 1: analysis; Phase 2: design of learning materials; Phase 3: development and Phase 4 evaluation. Procedure in Phase 4 involves pilot test and update learning materials in NETA prototype before formative assessment by form one student after completing task using NETA prototype to assess ease of use and motivation to use NETA prototype.

\section{Research Sample and Sampling}

A purposive sample, also commonly called a judgmental sample, is one that is selected based on the knowledge of a population and the purpose of the study (Ashley Crossman, 2013). Students are selected from a Penang secondary school from various knowledge to use iPad. In formative evaluation, questionnaires were distributed to 40 students from form one secondary school after using NETA prototype to assist Malay grammar learning to evaluate it. It is to study the acceptance, ease of use and motivation to use NETA Prototype as an assisting tool in learning Malay grammar.

\section{Instructional Materials}

Four phases were included in the design of the learning material grammar. Researcher determines the type of learning required by the students. Goals were analyzed to identify the skills that must be learned and steps to be followed by the students to the learning process (Dick \& Carey, 1985). In identifying instructional goals, the first step in the Dick and Carey model is to determine what the students can perform when completing training (Dick \& Carey, 1985: 5). In identifying specific skills and steps in learning, it is necessary to identify specific skills that students have to prepare before development begins (Dick \& Carey, 1985). In phase three, the strategy applied in the delivery of learning materials in NETA prototype take place. Teaching strategies include determine which media are used to achieve the objectives (Dick \& Carey, 1985). Strategies based on existing knowledge in the learning process, the content being taught and its students on materials (Dick \& Carey, 1985). Phase four is the implementation of formative assessment of learning material in NETA prototype. Grammar learning materials that have been evaluated to be updated and improved before being implemented in secondary school. Data from formative assessment is used to review the validity of the acceptance, ease of use and motivation of using NETA Prototype as an assisting tool in learning Malay grammar. 


\section{Research Instruments}

The research instrument used in this research was a questionnaire which was administered after the learners are familiar with NETA prototype. Instrument items for the questionnaire are adapted from User Acceptance Test, IMMS Keller and Nielsen Usability Test. The questionnaire consists three sections:

- Section I - Demography (2 questions)

- Section II - Student's Tablet Using Skill (2 questions)

- Section III - Motivation \& Ease of use of NETA Prototype (26 questions)

Originally, the IMMS (Keller, 1983) was developed to measure learners' motivation towards instructional materials provided to them. However, since the origin is in the ARCS motivational design model that is based on human motivation literature, it can be used to measure attitude towards a treatment (Seung, 2006). In this research the modified IMMS statements refer to the specific situation-NETA prototype. The modified IMMS reflects some changes in vocabularies for instance; instead of instruction and learning, task and activities were used. During the pilot test, the Cronbach's alpha coefficient of the scale was found to be .832 indicating a relatively high internal consistency of the items.

\section{Research Procedure}

Researcher discusses the steps taken to collect data. Researcher conducted a questionnaire to obtain information about the needs of students who learn form one Malay grammar. Therefore, the needs analysis of the form one student to survey opinion is required. The survey data collected through verbal respond in phase one. Studies on learning problems of students in Malay Language must be done to help students who are weak in the Malay language, especially in the aspect of grammar. Grammar learning materials need to be developed for the use of students as either supplementary learning materials use in schools or at home.

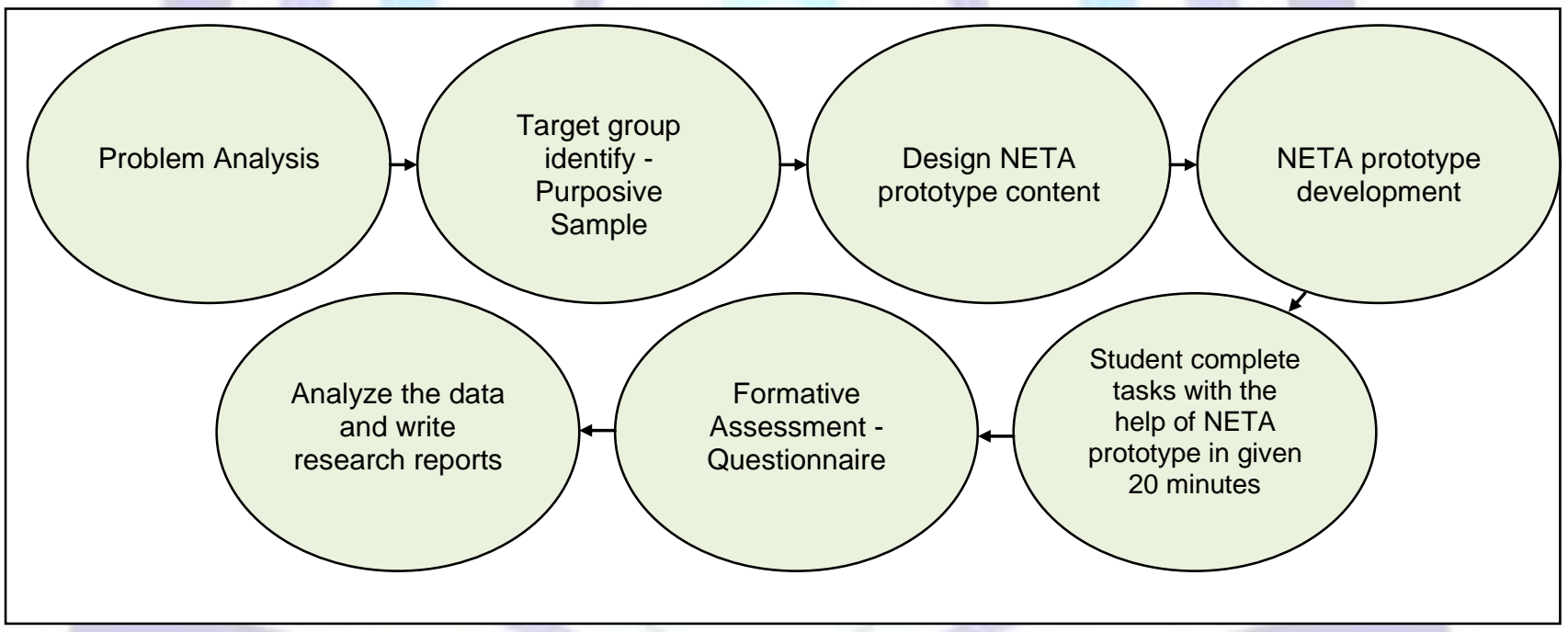

Figure 3. Flow Chart of Research Procedure

\section{Data Collection}

Data collection was carried out according to the phases of the study. Each phase has different data collection methods. Summary of data collection is as follows:

Table 1. Formative Evaluation Details

\begin{tabular}{|c|c|c|c|}
\hline Level & Task & Instrument & Technique \\
\hline $\begin{array}{c}\text { Phase 4 - } \\
\text { Formative } \\
\text { Evaluation }\end{array}$ & $\begin{array}{c}\text { Study the ease of use and } \\
\text { motivation using NETA Prototype } \\
\text { as an assisting tool in learning } \\
\text { Malay grammar }\end{array}$ & Questionnaires & $\begin{array}{c}\text { Answered by } 40 \text { form one } \\
\text { students from a secondary } \\
\text { school }\end{array}$ \\
\hline
\end{tabular}

\section{DEVELOPMENT}

\section{Hardware and Software in App Development}


The development of NETA prototype based on Dick and Carey model. Constructivist theory integrated into content development. Fitt's law and Gagne's Nine Events of Instruction integrated into user interface design of the app. Criteria used in selection of the hardware and software to develop a NETA prototype is based on its stability and availability. An iPad 3 and a $2.0 \mathrm{GHz}$ speed computer with 8GB RAM capacity and 256GB hard disc size were used. App Cooker is the name of the software that was used to develop this prototype. Software produced is categories as native app which helps in producing stable user experience.

\section{Gagne's Nine Events of Instruction}

Gagne(1965) in his book The Conditions of Learning, identified the mental conditions for learning. These were based on the information processing model of the mental events that occur when adults are presented with various stimuli. Gagne created a nine-step process called the events of instruction, which correlate to and address the conditions of learning. This model would be used to develop NETA prototype.

\section{Gaining Attention}

The app starts with an engaging opening sequence. A space theme is used to play off the new software product's name, NETA prototype. Inspirational music accompanies the opening sequence, which might consist of a shooting star or animated logo. It explains how important it is to learn Malay grammar and how to use the NETA prototype. It also emphasizes the benefits of the NETA prototype, which addresses the know problem.

\section{Informing learners of objectives}

Second pop-up windows with the following learning objectives appear immediately after the introduction. Upon completing this lesson, students were able to: List the benefits of the NETA prototype; Print paper copies of all reports.

\section{Stimulating Recall of Prior Learning}

Students are called upon to use their prior knowledge of other software applications to understand the basic functionality of the NETA prototype. They are asked to think about how they start, close, and print from other programs such as their word processor, and it is explained that the NETA system works similarly. Representatives are asked to reflect on the process of the old lead-tracking system and compare it to the process of the new electronic one.

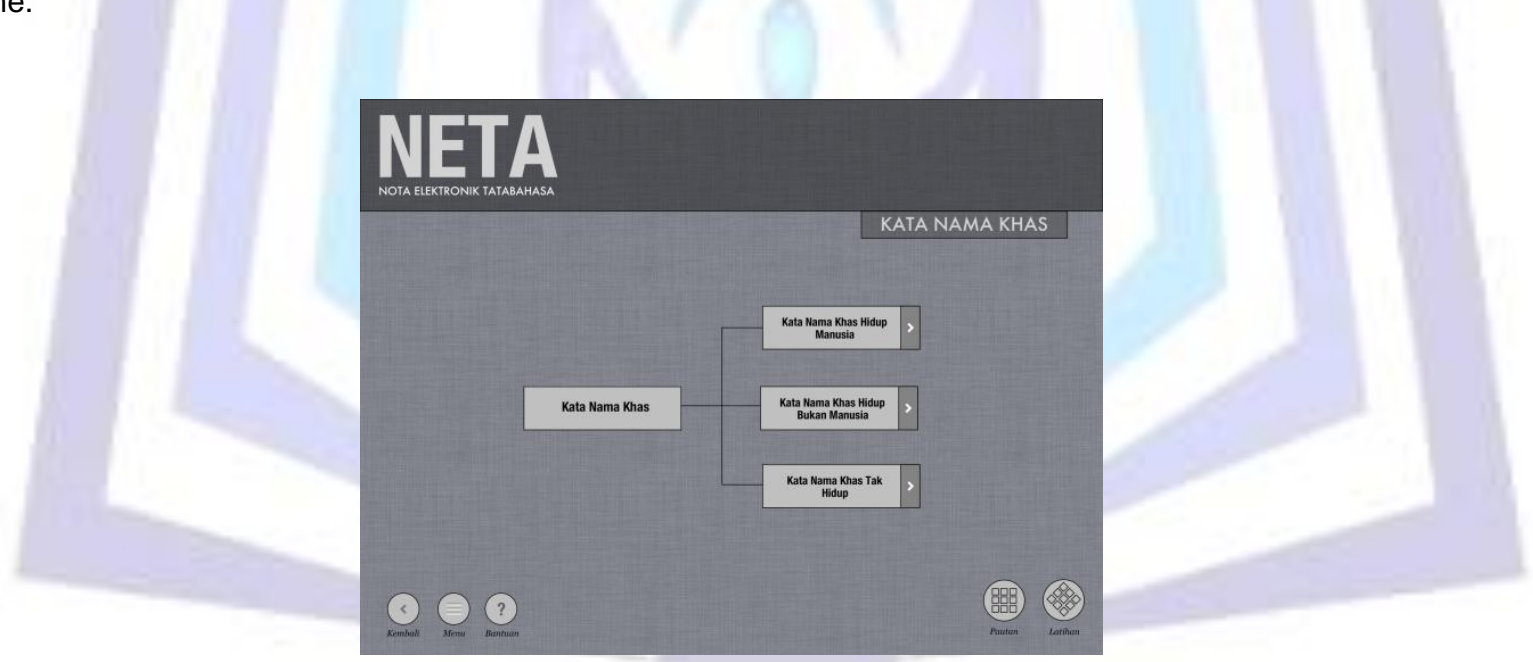

Figure 4. Screen capture of sub menu which called upon users prior knowledge

\section{Presentation the Content}

This event of instruction is where the new content is actually presented to the learner. NETA prototype content was chunked and organized meaningfully, and typically is explained and then demonstrated. To appeal to different learning modalities, a variety of media used if including text, graphics and audio narration. After the description, a simple demonstration is performed. 


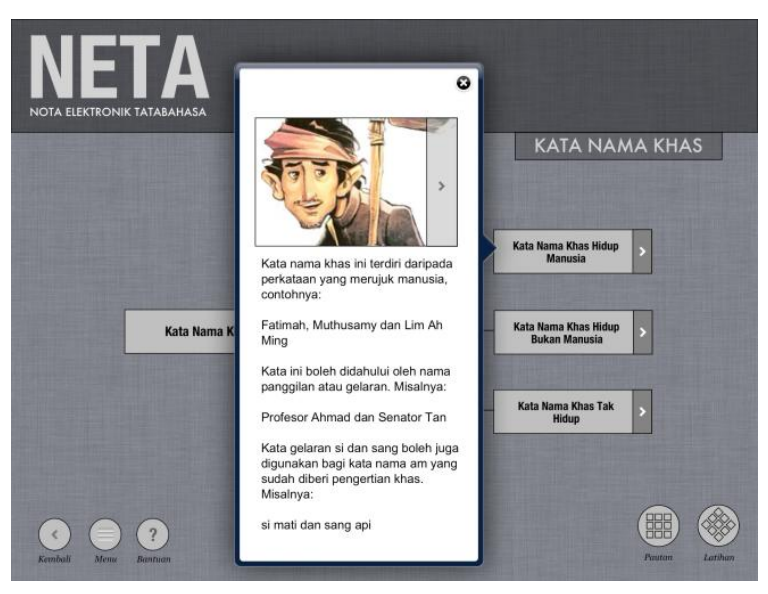

Figure 5. Screen capture of the content screen of NETA prototype

\section{Providing Learning Guidance}

With each NETA feature, students were shown a variety of ways to access it - using short-cut keys on the keyboard, drop-down menus, and button bars. Complex sequences are chunked into short, step-by-step lists for easier storage in long-term memory. To help learners encode information for long-term storage, additional guidance should be provided along with the presentation of new content. Guidance strategies include the use of examples, non-examples, case studies, graphical representations and analogies.

\section{Eliciting Performance (Practice)}

Students are asked to practice with realistic, controlled simulations. Students are required to use the tap on the correct on-screen buttons and options to generate the report.

\section{Provide Feedback}

Students are given guidance as needed. When they perform operations correctly, the simulated NETA prototype behaves just as the live application would. If the student makes a mistake, the tutorial immediately responds with a clue, and a pop-up window explains and reinforces the correct operation.

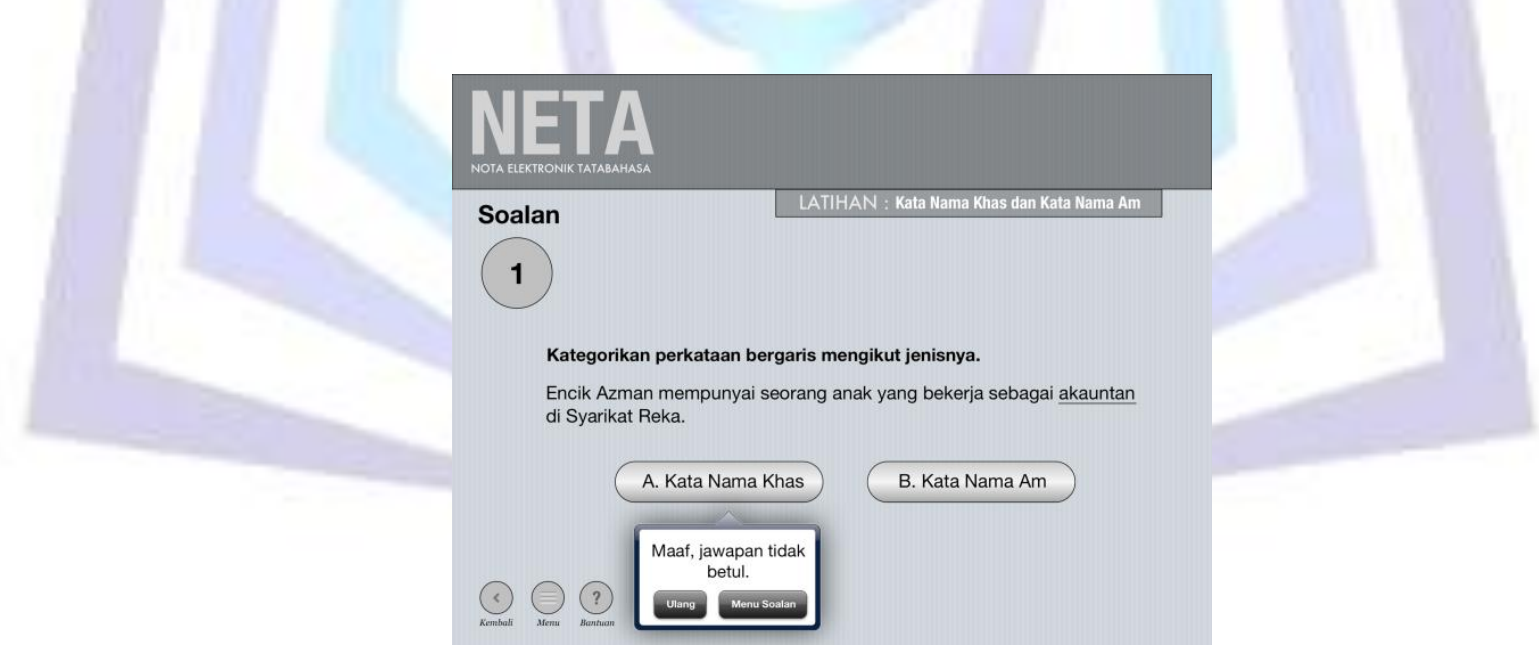

Figure 6. Screen capture of NETA prototype provide feedback when tap to a button

\section{Assessing Performance}

After all lessons are completed, students took the post-test. The training program displays a completion certificate. The assessment questions are directly tied to the learning objectives displayed in the lessons.

\section{Enhancing retention and Transfer of Learning}

While the NETA prototype is relatively easy to use, additional steps are taken to ensure successful implementation of the app. These features include "wizards", which are step-by-step instructions on completing complex tasks. Additionally, the training program is equipped with a content map, an index of topics, and a search function.

\section{Fitts' Law}




\section{ISSN 2278-5612}

\section{Bigger Is Not Always Better}

Increasing the absolute or relative size of a button to make it easier to click is also a popular technique among designers for communicating priorities within the interface and prompting or calling users to perform a particular action.

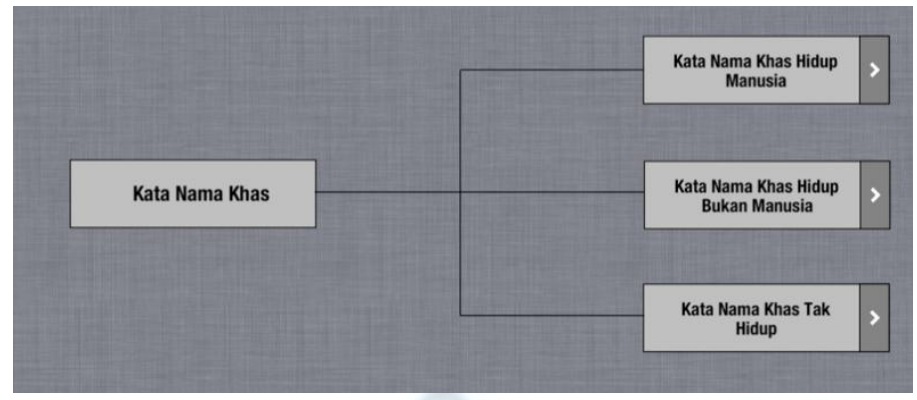

Figure 7. Screen capture shows relative size of buttons make it easier to click.

\section{Movement and Distances}

A second statement one can deduce from Fitts's Law is that the closer a target, the faster it is to acquire. If developer place the links and buttons, users are most likely to access on a regular basis next to each other, rather than distribute them across the interface, students speed up interaction by reducing the amount of pixels the cursor have to travel.

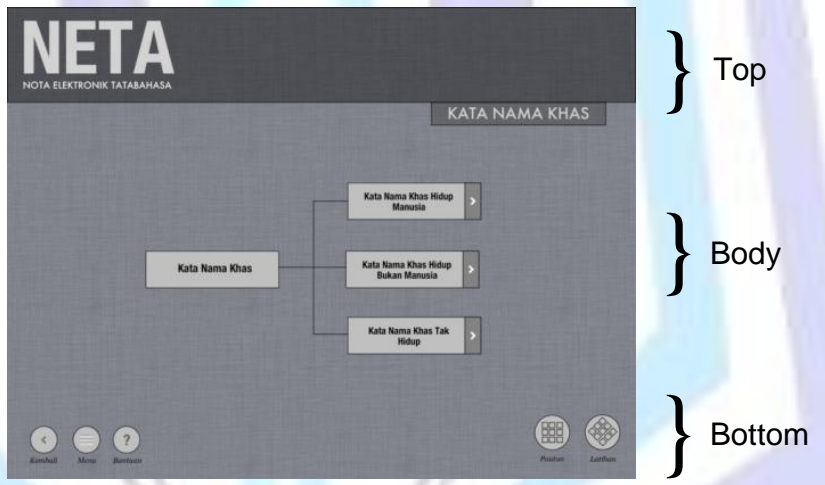

Figure 8. Screen capture of buttons arrangement at the bottom of the screen.

\section{Prime Pixel}

The concept of prime pixels states that some pixels are faster to acquire than others. Corners and edges of the screen are especially fast to access. However, the fastest-to-acquire pixel in any situation is simply the pixel at the current cursor position, which has lead to the introduction of the right-click context menu into human-computer interaction.

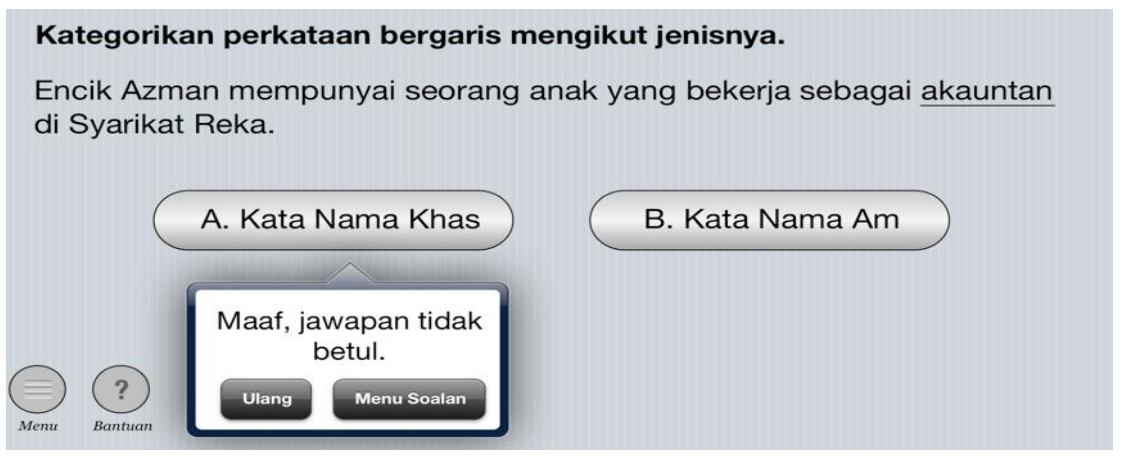

Figure 9. Screen capture shows a link arranged below the last clicked button. 


\section{Grouping Items}

It's important to keep interface items that are similar in close proximity to each other to reduce the distance between them, and thereby improving usability under the Fitts' law model.
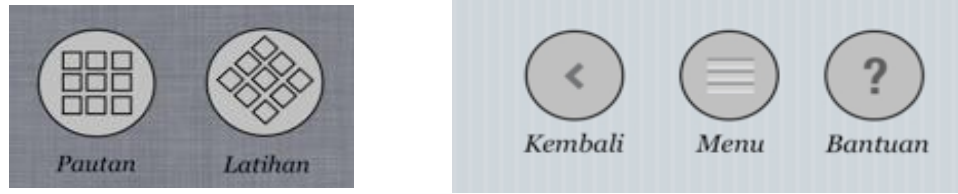

Figure 10. Screen capture shows grouped interface items that are similar in close proximity.

\section{FINDINGS}

The narration and explanation of the data were as follows: The means equal to or above 4.07 indicated a threshold for good agreement for item whereas those equal to or below 3 was considered to have a lower importance given by the students for the item in question.

All thirteen items to assess motivation to use NETA prototype show positive indications towards its use. Many do not agree that the writing style was shown boring (2.15). It is well accepted opinion because boredom is the aspect that is often identified as the source of language-based subjects failed to get a place in the hearts of students. However, there are items that need to be addressed such as too much information on an interface (3.25). It can be rectified by giving concise information.

The questionnaire used in this study included three parts containing 26 items related to motivation and ease of use of NETA prototype. The survey asked the participants to rate each of the items following on a 1-5 Likert Scale (Strongly disagree, Disagree, Not Sure, Agree, Strongly agree). SPSS was used to find out mean scores (along with standard deviations) of the items.

Table 2. Mean and Standard Deviation Value for Item on Student's Motivation to Use NETA Prototype in Assisting the Learning of Malay Grammar

\begin{tabular}{|c|c|c|c|}
\hline Items & & Mean & St Dev. \\
\hline 1 & When I first looked at this app, I had the impression that it would be easy for me. & 4.65 & 0.736 \\
\hline 2 & There was something interesting at the beginning of this app that got my attention. & 4.4 & 0.672 \\
\hline 3 & This app was more difficult to understand than I would like for it to be. & 1.83 & 0.903 \\
\hline 4 & Completing task using this app gave me a satisfying feeling of accomplishment. & 4.48 & 0.751 \\
\hline 5 & It is clear to me how the content of this app is related to things I already know. & 3.78 & 0.862 \\
\hline 6 & $\begin{array}{l}\text { Many of the interfaces had so much information that it was hard to pick out and } \\
\text { remember the important point. }\end{array}$ & 3.25 & 1.256 \\
\hline 7 & This app is eye-catching. & 4.63 & 0.628 \\
\hline 8 & $\begin{array}{l}\text { The wording of feedback after the exercises and the comments in this app helps me } \\
\text { feel rewarded for my effort. }\end{array}$ & 4.45 & 0.639 \\
\hline 9 & $\begin{array}{l}\text { The variety of examples, exercises, illustrations, etc., helped keep my attention on } \\
\text { the app. }\end{array}$ & 4.57 & 0.636 \\
\hline 10 & The style of writing is boring. & 2.15 & 1.292 \\
\hline 11 & $\begin{array}{l}\text { I could relate the content of this app to things I have seen, done, or thought about in } \\
\text { my own life. }\end{array}$ & 3.93 & 0.694 \\
\hline 12 & There are too many words on each interface that makes it irritating. & 2.05 & 0.815 \\
\hline 13 & $\begin{array}{l}\text { The good organization of the content helped me be confident that I would learn } \\
\text { Malay grammar using this app. }\end{array}$ & 4.6 & 0.545 \\
\hline
\end{tabular}


Key: 1 - Strongly disagree; 2 - Disagree; 3 - Not sure; 4 - Agree; 5 - Strongly agree

Table 2 shows that following points need special attention since these results represent what motivated students to use NETA prototype; The first impression that this app would be easy for the user (4.65); The beginning of this app got user's attention (4.4); Completing task using this app gave user a satisfying feeling of accomplishment (4.48); This app is eye-catching (4.63); The wording of feedback after the exercises and the comments in this app helps user feel rewarded for his/her effort (4.45); The variety of examples, exercises, illustrations, etc., helped keep user's attention on the app (4.57); The good organization of the content helped user be confident that he/she would learn Malay grammar using this app (4.6).

Table 3. Mean and Standard Deviation Value for Item on the Ease of Use of the NETA Prototype in Assisting the Learning of Malay Grammar

\begin{tabular}{clcc}
\hline Items & & Mean & St Dev. \\
\hline 1 & Learning to operate NETA prototype would be easy for me. & 4.65 & 0.58 \\
\hline 2 & I would find it easy to get NETA prototype to do what I want it to do. & 4.37 & 0.807 \\
\hline 3 & My interaction with NETA prototype would be clear and understandable. & 4.7 & 0.464 \\
\hline 4 & It was easy to become skillful using NETA prototype. & 4.53 & 0.506 \\
\hline 5 & It took a reasonable amount of time to complete most task. & 3.68 & 1.185 \\
\hline 6 & Procedures were simple and required a minimum number of steps. & 4.23 & 0.891 \\
\hline 7 & Errors were easy to recover from. The error messages gave useful information. & 3.82 & 1.01 \\
\hline 8 & The interface, menus and screens, were laid out in a logical fashion. & 4.53 & 0.554 \\
\hline 9 & The prompts and error messages were appropriate in tone. & 4.38 & 0.838 \\
\hline 10 & Pacing was comfortable, neither too fast nor too slow. & 4.3 & 0.883 \\
\hline 11 & Command names and what the commands did were easy to remember. & 4.33 & 0.73 \\
\hline 12 & It is easy to remember how to perform tasks using NETA prototype. & 4.63 & 0.586 \\
\hline 13 & I would find NETA prototype easy to use. & 0.385 \\
\hline Kev 1 & - Strongly dsagree & 4.83 \\
\hline
\end{tabular}

Key: 1 - Strongly disagree; 2 - Disagree; 3 - Not sure; 4 - Agree; 5 - Strongly agree

Table 3 shows that following points need special attention because it represent the ease of use of NETA prototype in assisting the learning of Malay grammar; Learning to operate this app would be easy (4.65); It is easy to get this app to do what user want it to do (4.37); The interaction with this app would be clear and understandable (4.7); It was easy to become skilful using this app (4.53); Procedures were simple and required a minimum number of steps (4.23); The interface, menus and screens, were laid out in a logical fashion (4.53); The prompts and error messages were appropriate in tone (4.38); Pacing was comfortable, neither too fast nor too slow (4.3); Command names and what the commands did were easy to remember (4.33); It is easy to remember how to perform tasks using this app (4.63); User find this app easy to use (4.83).

Students were cumulatively agreed that NETA prototype is easy to use. It is followed by the second highest mean score about inherent error is easily overcome with a useful message. Both of these findings lead to the conclusion that clear communication and explanation of the problem faced by students could increase the ease of use of NETA prototype. Priority was also given to the interaction with NETA prototype which is clear and understandable (4.7). It is intertwined with the item on easy to remember how to perform tasks using NETA prototype with a mean score of 4.63 . High mean scores obtain from a group of young users easily express the app approach which does not burden the mind is preferable. It is an indication of why the item on interface having too much information is not getting a high mean score.

In summary, student's motivation to use NETA prototype was very high and they also found that NETA prototype is easy to use. The results achieved shows NETA prototype has a very high potential to be accepted by users. 


\section{DISCUSSION}

Student's motivation to use NETA prototype was very high. In term of motivation this findings is consistent with previous literature review. The study conducted by Syazwan Noordin, Wan Fatimah \& Yew Kwang Hooi (2011) was on a multimedia courseware using 3-Dimensional (3D) model for teaching a mathematical topic on Lines and Planes in 3-Dimensions. The study concludes that the latter group showed significant improvement in attention, response and recall of the content. Those findings can be related directly to the usability of NETA prototype. An app could be a great medium to deliver subject content because it helps student to be focus and level of recall of the content is high.

The findings of this research are also similar to Qais Faryadi (2012) who did an experimental research that was aimed at developing an interactive multimedia courseware to be utilized in Malaysian classrooms. A courseware for interactive instructional design for learning Arabic was designed. Although it uses different approaches in development of its software compare to NETA prototype but this study highlights the use of the application in the classroom had improved learning effectiveness. Recommendations for further research were made in this section are very accurate and needed.

Although NETA prototype was well received by the majority of students and realized it was still in prototype stage, the researcher still think there is a loophole to be repaired. Several previous authors have suggested that usability testing may not be appropriate to use as a yardstick for other techniques because it is not perfect, being subject to limitations of the laboratory environment, study design flaws, and evaluator biases (Hartson et al., 2003; Jacobsen et al., 1998; Newman, 1998). Thus, the comparison of several NETA prototypes could reveal even more insight into what users like or do not like about tablet-based apps. Therefore, a more in depth understanding of what users require is necessary. Because the NETA is meant to be a tool, it should not elicit frustration, as was the case in this study.

The few students who volunteered for this study affected the findings. Recruiting native iPad users in a small school created an obstacle in finding the appropriate participants. Although it would have been beneficial to have matched pairs based on age, this study's participant group was not appropriate for such an analysis. Because the tablet-based app in this study was a prototype, which lacked appropriate functionality in some regards, a certain limitation was the prototype itself. Having been designed by research and not professional computer programmers, the NETA prototype had certain simplicity of function that may have been avoided had professional work been completed for the app.

\section{Implication and Future Study}

The researcher presented and implemented NETA prototype development based on Fitts' Law to enhance usability. Researcher tries to find answers to two fundamental questions for this study: How is the student's motivation to use NETA prototype in assisting the learning of Malay grammar and how is the ease of use of the NETA prototype in assisting the learning of Malay grammar?

Answering the first question, the researcher founds strategies which increase the attention, relevance, confidence and satisfaction of the students for a instructional design which ensures the continuity of learning motivation (Keller, 1983) of NETA prototype believed to have a positive impact on students motivation. NETA ability to impress on their first experience is a key factor to motivate students. It is also agreed that NETA prototype is interesting in appearance. Approach in linking student's personal experience in using the prototype NETA has generated motivation to continue to use it. Students who feel unable to connect him with the software would not able to appreciate the experience. The wording of feedback after the exercises and the comments in this app helps user feel rewarded for their effort. Student's satisfaction is high when questionnaire items related to satisfaction achieved scores above the grand mean. The use of textual material (Keller et al, 1987) was found not to be boring. Diversity in examples, exercises and illustrations helps students to focus on the app. This diversity factor should be focused and refined to produce the next version of NETA.

Answering the second question, the researcher found NETA is easy to operate and the interaction between the user and the system is clear and easy to understand. The mean score for the item on opinion of the students that NETA is easy to use is highest among other items. NETA development based on Fitts' Law greatly influences the item for a simple procedure and steps taken are minimal. It also recorded one of the highest scored mean items. In addition, NETA is concerned about the signals and the language used was not being offensive to community feeling or sensitivity. NETA is also an app that was developed for use in a class setting. It is placed to master the Malay language grammar. At the same time, the ability of students to master the importance of obedience to rules and politeness in dealing with electronic equipment are also highly prized.

Apart from answering two main questions, the researcher also suggest the following recommendations to be considered for future study. The study which covers other aspects of the interface must be done. The need to diversify the scope of the study is needed. It can also be extended to other subject. Subjects supposedly boring and not interesting to learn can do the app-based learning. Other recommendations from the researcher are to produce an app for the wider group of students includes primary and tertiary level. It will able to answer more usability issues from different perspective of users. This last recommendation is no less important. Exploratory study in terms of how teachers and students using the app in the context of education would be an interesting area for study. It is very important to know the ability and interest that had been shown in owning a tablet in Malaysia were very high. However, the functions of the tablet app have never seen as a catalyst in transforming the education landscape in Malaysia. Attention should be given to this development in the future study. 


\section{CONCLUSION}

One of the NETA strength agreed by students is its ability to translate their needs and facilitate the teaching and learning process. Researcher would like to emphasize the development of NETA to assist the teaching and learning of Malay language grammar achieved its target from motivational aspects. However there is still room to improve, especially the component connects to the existing experience in student's life. It has to be adjusted in line with demographic and exposure to information of the sample group. Setting a standard action which deemed appropriate for all students may have been the cause of this problem. The tablet-based NETA prototype app is visual medium, as demonstrated by the fact that so many users responded to visual clarity items. However, sound can be incorporated, particularly for warnings, reminders and alarms. In response to Wallen \& Mulloy's (2006) recommendation that WBTs (Web-Based Training programs) incorporate audio narration, future research could include a study that includes the visual clarity and sound.

Through the development of NETA, the question of how motivation and ease of use of NETA prototype helping students to learn Malay grammar successfully answered. This application would able to help those wishing to implement similar projects. The project also created an opportunity to get opinion from different demographic background students with an interface that has been updated.

\section{REFERENCES}

[1] Abdul Rashid Jamian Arab'ie Sujud (2001). Integrasi Media Pengajaran Bahasa dan Sastera. Kuala Lumpur: Sentosa Printing.

[2] Baharuddin Aris, Rio Sumarni Shariffudin and Manimegalai Subramaniam (2002). Rekabentuk perisian multimedia. Johor Bahru: Universiti Teknologi Malaysia Publisher.

[3] Dick W. and Carey L. (1985). The systematic design of instruction. London: Scott, Foresman and Company.

[4] Fayter D.(1998). Issues in training lectures to exploit the Internet as a teaching resource. Education \& Training, Vol. 40, No. 8, MCB University Press, Retrieved September 19, 2005 from MCB University Press, ISSN0000- 0912.

[5] Golian L.M. (2000). Utilizing Internet resources by educational professional in the new millennium. Information Technology and Libraries, September, 19,3, 136- 143: Retrieved August 31, 2005, from Pro Quest Educational Journal.

[6] Ismail Zain (2002). Aplikasi multimedia dalam pengajaran. Kuala Lumpur: Utusan Publications \& Distributors.

[7] Jamalludin Harundan Zaidatun Tasir. (2003). Multimedia dalam pendidikan. Pahang : PTS Publications \& Distributors.

[8] Jianfeng Wang \& Sylvain Senecal (2007). Measuring Perceived Website Usability. Journal of internet commerce. - Binghamton, NY: Haworth Press, ISSN 1533-2861, ZDB-ID 21369008. - Vol. 6.2007, 4, p. 97112

[9] Mohamed Amin Embidan Afendi Hamat (2004). Development of self-access Learning Management System. Dalam Hanafi dan Rozhan M. Idrus, Integrasi Reka Bentuk Instruksional dan Teknologi dalam Pengajaran dan Pembelajaran. Konvensyen Teknologi Pendidikan ke-17, Kuala Lumpur: Persatuan Teknologi Pendidikan Malaysia.

[10] Mohd Arif Ismail, Zamri Mahamoddan Norian Abdul Razak (2000). Multimedia dan aplikasinya dalam pembelajaran bahasa. Prosiding Konferen Antarabangsa dalam Pengajaran dan Pembelajaran. Strategi pengajaran dan pembelajaran di abad ke-21. Fakulti Pendidikan. Universiti Kebangsaan Malaysia. Vol.3, 2425 November 2000, hlm. 916-929.

[11] Mohd Jasmy Abd Rahmandan Ros Azura Jantan. (2002). Tahap penggunaan laman web Pendidikan di kalangan Guru-guru Bahasa Melayu. Prosiding Seminar Kebangsaan Profesion Perguruan 2002. Fakulti Pendidikan. Universiti Kebangsaan Malaysia. 3-4 Jun 2002, hlm.159-173.

[12] Nielsen, J. (1993a). Categories of Users and Individual User Differences. In Nielsen J. (Eds.), Usability Engineering (43-48). MA, USA: Academic Press, Inc.

[13] Nielsen, J. (1993b). The Usability Engineering Life Cycle. In Nielsen J. (Eds.), Usability Engineering (71115). MA, USA: Academic Press, Inc.

[14] Qais Faryadi (2012). The Architecture of Interactive Multimedia Courseware: An Empirical-Based Approach: Phase Two. International Journal of Humanities and Social Science Vol. 2 No. 15; August 2012

[15] Reaves, C. C. (1992). Statistical Decisions. In Swain E. (Ed.), Quantitative Research for Behavioral Sciences (236-240). Canada: John Wiley \& Sons, Inc.

[16] Reviere, R., Berkowitz, S., Carter, C. C., Ferguson, C. G. (1996). Needs Assessment: A Creative and Practical Guide for Social Scientist. In Reviere, R., Berkowitz, S., Carter, C. C., Ferguson, C. G. (Eds), Introduction: Setting the Stage (pp. 1-11). London, UK: Taylor and Francis Itd. 
[17] Thompson, J. A. (1999). Investigating the effectiveness of applying the Critical Incident Reporting Technique to Remote Usability Evaluation. Unpublished thesis, Virginia Polytechnic Institute and State University, Blacksburg, VA

[18] Schmidt, R.A. (1991). Motor learning \& performance: From principles to practice. Champaign, IL: Human Kinetics Publishers.

[19] Seow, Steven C. (2005). Information Theoretic Models of HCl: A Comparison of the Hick-Hyman Law and Fitts' Law. Human-Computer Interaction. Sep2005, Vol. 20 Issue 3, p315-352. 38 p.8 Diagrams, 5 Graphs.

[20] Siti Aishah Hanawi, Noraidah Sahari @ Ashaaridan Hazura Mohamed (2002). Kajian perbandingan kesedaran, pengetahuan dan penggunaan ICT di kalangan guru- guru sekolah Bandar dan sekolah luar bandar. Prosiding Seminar Kebangsaan Profesion Perguruan 2002. Fakulti Pendidikan. Universiti Kebangsaan Malaysia, hlm.150-157.

[21] Syazwan Noordin, Wan Fatimah Wan Ahmad and Yew Kwang Hooi (2011). Article: Study of Effectiveness and Usability of Multimedia Courseware Integrated with 3-Dimensional Model as a Teaching Aid.

[22] International Journal of Computer Applications 16(4):20-27, February 2011. Published by Foundation of Computer Science.

[23] Wadsworth, B.J. (2004). Piaget's Theory of cognitive and affective development, (5 Eds). United States Of America: Pearson Education.

[24] White, H., McConnell, E., Clipp, E., Bynum, L., Teague, C., Navas, L., Craven, S., Halbrecht, H. (1999). Surfing the Net in Later Life: A Review of the Literature and Pilot Study of Computer Use and Quality of Life. The Journal of Applied Gerontology, 18(3), 358-378 